Woo, M. W. E (2006). Comparative study of staff development in academic libraries of Mainland China and Hong Kong. In C. Khoo, D. Singh \& A.S. Chaudhry (Eds.), Proceedings of the Asia-Pacific Conference on Library \& Information Education \& Practice 2006 (A-LIEP 2006), Singapore, 3-6 April 2006 (pp. 230-238). Singapore: School of Communication \& Information, Nanyang Technological University.

\title{
COMPARATIVE STUDY OF STAFF DEVELOPMENT IN ACADEMIC LIBRARIES OF MAINLAND CHINA AND HONG KONG
}

\author{
MEI WA ESTHER WOO \\ University Libraries, The University of Hong Kong, \\ Pokfulam Road, Hong Kong, People's Republic of China \\ E-mail: esther.woo@hku.hk
}

\begin{abstract}
The aim of this study is to conduct a comparison between the staff training and development (T \& D) of academic libraries in Mainland China and Hong Kong -- two systems developed under fastchanging cultural, political and socio-economic environments in the past century. This paper argues that socio-economic, cultural and technological changes are pushing the development of academic library systems in the two regions towards convergence. The comparison identifies differences and similarities in staff $\mathrm{T} \& \mathrm{D}$ policies and practices of academic libraries in the two regions, as well as the contributing factors. The analysis is supported by the results of a survey conducted by the author in 2005 . It concluded that the two systems share similar concerns and problems in many aspects, and one of the major contributing factors may be the size of the library.
\end{abstract}

\section{Background of the Study}

As in many people-oriented industries, human resource management (HRM) has long been a major area of research among libraries. A large number of works can be found on HRM from overseas librarians. The number of related articles published by library professionals in Mainland China is also on the rise in recent years. Nevertheless, HRM has never been an area much written about among librarians in Hong Kong. With China and Hong Kong reunified for almost a decade, the World witnessed significant changes in their cultural, political and socio-economical environment. It will be interesting to explore at this moment of time whether the development of the two library systems are heading towards convergence by looking into their HRM policies and practices. The target group of this study is the academic libraries in Mainland China and Hong Kong, meaning all non-profit-making university or college (institution of higher education or professional training) libraries in the two regions. The rationale for choosing this group of libraries are:

- the greater impact of information technology, education reforms and globalization on them as a single category of libraries;

- their manageable size in a small scale survey within a limited time frame and;

- their relatively good access to the Internet that will facilitate implementation of an online survey and subsequent data processing.

The time span to be covered by this study is confined to the modern historical period of People's Republic of China (PRC), viz. from 1970s to present so as to focus the discussion on library development after the chaotic Cultural Revolution period. The rapid changes in the socio-economic environment and information technology in this period of time also provide a good background for comparative study of the two library systems that were so different in the past and yet much more closer to each other after years of modernization.

\section{Issues affecting Staff T \& D in Academic Libraries}

\section{Socio-economic forces}

In general, there are three major forces at play, namely the national/regional socio-economic policies, globalization challenges and cultural change. National/regional socio-economic policies have the most direct impact among these forces. The best example is the funding policies that affect the direct allocation of institutional budgets which will in turn determine the investment on staff T \& D. No matter a library has a fixed or floating $\mathrm{T} \& \mathrm{D}$ budget, any major reduction or increase in the library funding allocation might have a domino effect on the sub-allocation to various library activities.

Some critics (Xie, 2003; Yang \& Wang, 2004; Yu, 2003) have pointed out that lack of investment in human resources is a major problem for many academic libraries in China. In a more direct way, underinvestment in human resources not only hinders the provision of hardware and software to staff $\mathrm{T}$ 
\& D. Bore importantly, it leads to poor remuneration for staff which affects the quality of staff or weakens the motivation for staff to develop towards a better future. However, one may also argue that $\mathrm{T} \& \mathrm{D}$ could serve as a motivator for staff when salary increase or promotion is out of the question due to various reasons such as poor financial situations or salary ceilings.

With the increasing demand for accountability in public organizations, many governments including the ones in China and Hong Kong have exerted more pressure on performance measurement and budget allocation policies of their subsidiary institutions. In most circumstances, this will mean increasing productivity and lowering costs by means such as automation, revised workflow, outsourcing, contract appointment, etc. Regardless of the means employed in each case, staff will more or less be affected in performing their duties and may need retraining to pick up new skills or knowledge before they can fully function in a new setting or with a piece of new equipment

On the other hand, socio-economic policies may appear in the form of educational reforms for 'excellence', 'enhanced international competitiveness', and 'quality' (Ngok \& Kwong, 2003). For example, the restructuring of education in China has led to massive integration of higher educational institutions. Academic libraries must somehow modify their HRM policies to cope with the issues created by the new organizational environment. The process may be as simple as reshuffling a few duties or as painstaking as reorganizing several libraries. Whichever is the case, staff T \& D will be a critical component in ensuring the smooth transition of academic libraries in these changes.

In the Hong Kong context, a major education reform will take place to restructure senior secondary and higher education, i.e. the " $3+3+4$ " academic structure (Education and Manpower Bureau, 2005). The reform will provide universities with an opportunity to review their fundamental philosophies and aims of undergraduate education. One of the major objectives of the new 4-year curriculum will be to enable graduates to possess the knowledge and skills necessary for career or further research in the future environment. Changes in curriculum and increase of undergraduate students will inevitably bring impact to the development of academic libraries in many aspects including staff T \& D.

Another major challenge affecting the development of academic libraries would be the impact of globalization on education. For instance, China's increasing integration into the world economy, such as joining the World Trade Organization (WTO), has imposed new pressures on education. These pressures, combined with decentralization and marketisation, have greatly affected the governance of education in China (Ngok \& Kwong, 2003). Academic libraries in China will have to improve the management and quality of existing staff in order to face external competitors among which many have been operating with market-oriented approaches or practices. Nevertheless, globalization will not only bring in competition but also opportunities. Whether individual libraries can make use of the opportunities to stand out or survive in the competition will much depend on the quality of their workforce.

Another major concern for librarians over globalization will be the legal responsibilities associated with copyright. The protection of copyright to be provided by WTO members has already aroused the attention of many Chinese (Peng, 2002) and Hong Kong librarians. Effective implementation of sophisticated copyright laws requires timely and comprehensive staff T \& D as the implication of the new legislation will be far reaching. Both librarians and users have to prepare for the new restrictions in duplicating or downloading any copyright information, be it in print or electronic format.

Globalization also means more interaction between nations and cultures. The language requirements for library workers will become higher as they are serving in the forefront during the introduction and exchange of foreign ideas. The influx of foreign students, scholars and faculties will create strong demand for services in foreign languages as well. In fact, language skill is a requirement frequently mentioned in the staff T \& D literature of Chinese librarianship (Long, 2004; Lou, 2004; Peng, 2004; Yao, 2004). In Hong Kong, the gradual increase of international and Mainland students in many tertiary institutions has already driven up the demand for staff training in English and Putonghua for many years.

\section{Cultural forces}

Cultural change is another sophisticated and yet not easily recognized factor influencing every institution and workplace. Academic libraries in China and Hong Kong are now subject to demand for higher accountability and performance management from the public. In the old days, users would be satisfied when the requested materials were retrieved or the answers needed were provided. Nowadays, people also ask for service quality in terms of timeliness, accuracy, user-friendliness, comfort, and so on. Library services and staff performance have to be evaluated and improved constantly. The 
quest of quality can be reflected by the increasing number of tailor-made or personalized services like the subject librarians, MyLibrary information service for individual users, etc.

However, knowing that the soul of any services is actually the attitude and skills of the providers, many academic libraries have come to realize that efforts must be made in changing the mindset and working attitude of staff in order to ensure successful implementation of library programs. Training in professional ethics is especially a popular topic in Chinese library literature (Tan, 1997; Wang, 2002; Wang \& Han, 2004). It is especially worth-noting that the government job allocation system in China has resulted in many library posts assigned to unqualified or even uninterested job holders. The situation is even worse with the lack of a HRM system that can motivate employees with better performance. In order to modernize their workforce, there is an urgent need for Chinese academic libraries to improve the ethical standards of their staff.

Though being admired by their Mainland counterparts for their high quality workforce, there are still worries among academic libraries in Hong Kong. The traditional mindset that academic institutions should be different from commercial setups might serve as an obstacle to attempts for shifting to a customer-oriented service approach. It is very difficult if not impossible to convince those staff with the old thought that a library user should be treated like customers who have paid for the service.

Facing more pressure in peer competition and resource allocation, modern libraries have adopted a more proactive role in operation and development. Marketing of services, outreaching to potential user groups and innovative management are no strange concepts to librarians in China and Hong Kong. To survive and thrive in the local tertiary educational sector, many academic libraries in these two regions have started promoting their services and reaching out to users or potential customers. Apart from subject and library knowledge, librarians have to possess very good communication and interpersonal skills, and sometimes even marketing skills. T \& D in these areas has become more popular in these days.

\section{Technological advancement}

The arrival of the age for information and technology has completely changed the traditional way of library operation. The new hybrid libraries possess both print and electronic resources. Digital technology creates a virtual new world of knowledge without walls or even personal contacts. Different forms of information can be integrated seamlessly to facilitate access by users from different corners of the world. All these user-friendly services are actually collected efforts of library workers and information specialists under a complex and turbulent environment. To respond to the evolving user needs in the new information era, academic librarians must closely follow the technological trend and plan strategically for the future.

In the ever-changing electronic environment, the library and information workforce must possess a skill set of increasing breadth and depth. Apart from professional knowledge and skills, individual and people skills, business and management knowledge and skills are important assets for librarians in the knowledge economy (Corrall, 2004). Riding on the fast lane of the technology highway, Hong Kong academic libraries have good experience in handling relevant changes. The advanced infrastructure of these libraries enables workers to practice and upgrade their knowledge almost without much hassle. Their Mainland counterparts however may not be so fortunate in each case. Owing to limitation in infrastructure or technological know-how in some remote areas, there is still a significant gap in the electronic service provision of Chinese libraries as compared with those in advanced countries. Internal variation among libraries is also of big concern given the vast difference in financial and human resources between institutions in rich and poor provinces. Nonetheless, many library professionals in Mainland China have realized the problem (Jia \& Li, 2002; Yao, 2004) and tried to tackle it in different ways including personalized staff $\mathrm{T} \& \mathrm{D}$, innovative technology management, collaborative development, etc. (Chen, 2002; Ren, 2003; Zhu \&Cheng, 2002).

Furthermore, the rapid development of the publishing industry has posed enormous challenges to academic librarians engaging in collection development and acquisition worldwide. In addition to product details, librarians need to have in-depth knowledge about the sophisticated pricing model and purchase options to negotiate with international vendors. They also have to track the usage and license entitlements of electronic resources to safeguard the interests of their libraries. All these jobs call for a novel spectrum of competences that can hardly be found in any single traditional library post. T \& D will therefore be essential to prepare existing staff to take up such new challenges. 


\section{Other contributing factors}

Some research has shown that HRM in large and small organizations is fundamentally different. The usual argument is that as a result of the limitation in resources of smaller organizations, their investments in staff T \& D will be comparatively lower. Researchers like Sadler-Smith et al. (1998) have tried to identify patterns of T \& D in relation to the size of organization. Hill and Stewart (1999) and Sadler-Smith et al. (2000) have argued that the resource constraints within many smaller organizations might mean that they sometimes fail to maximize the potential of learning. Matlay (2000) identified two groups of factors that affect the provision of training in small organizations. Direct factors included market position, economic conditions and availability of relevant training. Indirect factors included costs of training and time constraints. A minority of organizations indicated lack of in-house instructors, lack of trainee motivation or trainee interest as limiting factors.

The attitude and role of the manager are found to be crucial factors in the T \& D of small organizations. Hendry et al. (1995) highlighted affordability, ownership and control, fear of poaching, limited horizons and the pressures of growth as constraints on occupational learning in small organizations. They also identified a general reluctance in small medium enterprises to spend money on training with the allocation of resources for training being ad hoc up to the point at which the firm reaches about one hundred employees in size. Matlay's research mentioned above suggests that managers make virtually all of the important decisions related to workforce training. Walton (1999) pointed out that the educational experiences of some managers in small organizations may reinforce a generally negative attitude to $\mathrm{T} \& \mathrm{D}$ that can make it difficult to convince these key stakeholders of the value of training.

In their recent studies, Sadler-Smith and Lean (2004) found positive correlations between organization size and certain major T \& D activities (planning and evaluation, implementation, and design) as well as delivery methods (off-job T \& D). They also reconfirmed the prime responsibility of managers of small organizations for almost all T \& D activities. However, some issues can be further explored such as whether small firms recruit those individuals that have been assessed through the selection process as not needing additional training. Sadler-Smith observed that in a highly resource-constrained internal environment, managers might be more likely to employ individuals who are able to perform effectively and quickly with minimal induction training or additional skills development needs. The researchers concluded by suggesting a broader perspective to include issues such as recruitment and selection in future research.

According to the American Society for Training and Development (ASTD), industries spent an average of $1.4 \%$ of payroll on training while two percent is the minimum recommended by ASTD in early 1990s. A survey of the Urban Library Council (ULC) in 1993 found that $60 \%$ of their members spent less than $1 \%$ of their personnel budgets on staff development. The data collected by the American Library Association in 2001 indicated a higher spending level among academic libraries (see Table 1 below) with an average of 1.26 percent of total payroll spent on staff development. Academic libraries in four-year colleges provided the largest amount ( 1.53 percent) of payroll on staff T \& D. However, the level was still low as compared to American businesses which spent an average of 1.8 percent of payroll on training in 1999.

Table 1. Expenditures for Staff Development and Training as Percentage of Total Payroll

\begin{tabular}{|l|l|l|l|l|l|}
\hline Type of Library & No. & Low \% & Median \% & Mean \% & High \% \\
\hline Two-year college & 95 & 0.12 & 0.90 & 1.26 & 5.62 \\
\hline Four-year college & 79 & 0.07 & 1.26 & 1.53 & 6.28 \\
\hline University & 178 & 0.03 & 1.08 & 1.35 & 10.34 \\
\hline
\end{tabular}

Taking into consideration the arguments and findings of the above research, attempt was made in a study conducted by the author in 2005 to find out whether there was any relationship between the level of support to T \& D and the staff size of academic libraries in China and Hong Kong. It is also expected that the survey data can help to identify differences and similarities in staff $\mathrm{T} \& \mathrm{D}$ policies and practices of the two library systems. 


\section{The Survey}

\section{Survey methodology}

The survey mentioned was conducted between April and May 2005. Research literature often uses the number of staff as the major criterion in classifying the size of organizations. However, the definitions of small organizations adopted in different regions reflect tremendous variation. For instance, Beaver and Hutchings (2004) pointed out that in the Workplace and Industrial Relations Survey (WIRS) and Australian Workplace and Industrial Relations Survey (AWIRS), small businesses are defined as those that employ 100 people or fewer. The North American National Organizational Survey (NOS) defines small businesses as organizations that employ 450 employees or fewer, while the European Commission defines small business as 49 employees or fewer and refers to those with fewer than 10 employees as very small or micro enterprises.

In the Hong Kong context, the definition of Small-Medium Enterprises (SMEs) adopted by researchers is also the number of persons engaged which may vary from industry to industry (1999): Taking into account the definitions adopted by various researchers as well as the actual staff establishment of libraries in China and Hong Kong, all respondents of the current study were requested to classify their size into the following categories according to their employee headcounts:

- Large libraries- more than 100 employees

- Medium libraries- 50 to 100 employees

- Small-medium libraries- 10 to 49 employees

- Small libraries- less than 10 employees.

The directors or management of target libraries were invited to participate in the survey via direct email messages. A list of 21 Hong Kong academic libraries were obtained from the 1996 publication Libraries and information centres in Hong Kong which was the most comprehensive library directory in Hong Kong by the time. As for the target libraries in Mainland China, email invitations were issued to over 450 academic libraries in various provinces and autonomous regions by using an online list of postsecondary and major libraries published by the Tsinghua University. Email addresses of the library directors or management were obtained by visiting each of the institution's homepage. An email invitation was then issued to each of the addresses informing the potential participants the purpose and deadline of the online survey. Link to the online survey questionnaire was given to facilitate their access.

The independent variables of this study include financial situation, staff size and culture of an organization such as perception of the management on staff T \& D. On the other hand, the dependent variables are the variation in staff $\mathrm{T} \& \mathrm{D}$ policies and practices, e.g. the different opportunities offered to and requirements imposed on upper and lower level staff, the contents and format of T \& D programs, etc.

The response rates from libraries in Mainland China and Hong Kong are 4.8\% (8) and 38\% (22) respectively. Most of the respondents (28) are libraries of universities or research institutes. In terms of library size, the overall proportion of respondents from large, medium and small to small-medium sized libraries are $60 \%(18), 26.6 \%(8)$ and $13 \%(4)$ respectively. The response from small and smallmedium sized libraries is fairly low. The possible reasons of the poor response from these libraries may be their lack of any formal staff T \& D programs, or relevant knowledge and experience, thus reducing their interest in participating in the survey. Potential respondents from those libraries may also find the questionnaire too 'overwhelming' as the scale of their T \& D programs may not be large enough to provide meaningful input.

\section{Major findings}

The survey posed 20 questions under four sections, namely 'Background Information', 'Staff Training and Development Policies', 'Staff Training and Development Investments and Practices' and 'Challenges for Staff Training and Development'. Major findings of the survey are summarized and analyzed below.

\section{Background information}

In both China and Hong Kong, the numbers of staff with formal library or information science qualification in respondent libraries are on the low side. Only a couple of libraries indicate that more than half of their staff members have formal library qualifications. 
Respondent libraries in both regions show a similar pattern in the historical development of their staff T \& D programs. Most of the libraries started their programs in the 1990s during which period the idea of Strategic Human Resource Management started to flourish. There are also some pioneers and laggards, showing a fairly common statistical result.

\section{Staff training and development policies}

Almost all respondents indicated that the library management decides on their T \& D policies. Only one library said that its school management dominates the decision making. Another respondent pointed out that its management was apathetic to staff $\mathrm{T} \& \mathrm{D}$ needs. Therefore, no decision was made at all in that library. The overall results show that policy making on staff $\mathrm{T} \& \mathrm{D}$ matters is usually under the control of the academic libraries themselves. The situation is even so in the case of Hong Kong.

The overall order of priority for T \& D objectives given by respondents in China and Hong Kong is very similar, indicating that libraries share common values in many of their staff T \& D objectives. With the exception of staff motivation and staff retention, the average score for each objective is on the high side. The highest average scores for the three objectives 'to help staff to keep current and reduce skill gaps', 'train up new staff' and 'improve service quality' suggest an emphasis on consistent provision as well as continuous improvement of service quality. Some difference can however be identified between the Mainland and Hong Kong libraries. For example, the former accord highest priority to the training of new staff while the latter focus more on the T \& D of existing staff. This may somehow be related to the different staffing composition or situations of the two regions. The high proportion of staff without formal library or information science qualification in China and the rapid development of Mainland academic libraries in recent years have somehow explained the critical need of training for new recruits. On the other hand, the relatively high score from Hong Kong respondents for the objective 'to cope with organization's future development' reflects their perception of human resources as a major asset to the mother institution. Staff T \& D will therefore be treated as a strategic tool to support organization development.

Despite the different staff grading structures in Mainland China and Hong Kong, the level of support rendered to different categories of staff is fairly similar. Senior staff such as research librarians, deputy research librarians and librarians in China and their counterpart professional librarians in Hong Kong all receive better support from the respondent libraries. In most cases, they are given support in both training and development. Without much surprise, the level of support for casual helpers is the lowest among all categories. A comparison between the response from Mainland and Hong Kong libraries shows that the latter's support for staff T \& D is more comprehensive in terms of staff categories. A majority of the Hong Kong respondents indicated that training will also be provided to casual helpers.

There is some difference between the libraries in Mainland China and Hong Kong regarding their major reason for not providing support to certain group(s) of staff. For Chinese libraries, the most important issue is insufficient resources, meaning that they recognize the needs of the affected staff but are not able to meet the demand due to limited resources. The Hong Kong respondents, on the other hand, do not perceive that there is a need for those affected staff (mainly casual helpers) for the moment. The average scores for other reasons are fairly low, indicating that they are not of major concern for the respondents.

It is interesting to note from the results that professional T \& D requirements in China and Hong Kong are quite different. Given that most Hong Kong librarians have obtained professional qualifications before they entered the field and quality of staff there is comparatively higher as a result of recruitment by competition, there might be no perceived need of re-certification or re-testing for existing staff. However, in order to ensure the service quality of a workforce with diverse backgrounds and professional qualifications, it will not be a surprise to find that some Chinese libraries have imposed the requirements of re-certification or re-testing on existing staff.

The findings also reveal the more demanding professional T \& D requirements for librarians and deputy research librarians in China as well as professional staff in Hong Kong. This is actually an expected outcome as these staff members are the backbone of these libraries in the near future. With a view to occupying strategic posts, they should demonstrate above average competence and attributes in carrying out current duties.

A total of 21 Mainland libraries and 7 Hong Kong libraries indicated that they have evaluation on staff T \& D programs. The overall results shows that the program evaluation in respondent libraries 
from China tends to rely more on the feedback and opinions of the upper management. The importance attached to the evaluation tools declines as the openness of the tools increases, indicating that the process is still quite restrictive and centralized. In the case of Hong Kong libraries, the variation is less significant.

\section{Staff training and development investments and practices}

A majority of the respondents replied that they have staff/a library unit appointed to take care of staff T \& D. However, only half of the responsible personnel in respondent libraries from both China and Hong Kong have formal training in HRM or related disciplines, implying that the duties are sometimes taken up by staff not as a major duty or without much support from the management. Funding is another major concern for staff T \& D. The results reflected that the situation for respondent libraries in Hong Kong is much better than their Mainland counterparts. While all Hong Kong respondents are supported by a stable or dedicated funding for their T \& D programs, over one-third of the respondents from China indicated that they are not entitled to this kind of support.

Among those libraries that have stable financial investment on staff T \& D, the levels of resources invested vary quite drastically among the Chinese respondents. About half of them invested over $1 \%$ of their total staffing budget on T \& D. However, there is also a quite a number of them which invested an annual average of less than $0.1 \%$. In comparison with the U.S. average of $1.26 \%$ in 2001 as mentioned earlier in this paper, the level of investments among Hong Kong respondents is on the low side which might be attributed to the poor budgetary condition of Hong Kong libraries in recent years. Another possibility could be that fewer resources might be required for a well-trained workforce.

As regards the most popular T \& D topics and formats in Mainland and Hong Kong academic libraries, the trends show that while respondents from both regions adopt similar formats in delivering their programs, the focus of content is varied. The Mainland libraries tend to provide practical training like IT, library standards and ethics whereas the Hong Kong respondents have a more balanced mix. The most remarkable difference will perhaps be the emphasis on management and interpersonal skills. The results somehow suggest a trend of divergence in the T \& D directions as well as management philosophy of the two systems.

In the evaluation of staff T \& D programs, libraries in Mainland and Hong Kong seem to adopt quite different ways in handling the process. The former takes a more all-round approach and gives similar weighting to the opinions of various stakeholders including the participants themselves, their colleagues and library patrons. In the case of Hong Kong respondents, the methods used tend to be more selective with more focus on the opinions from participants and performance of these people. As comprehensive evaluation will require more time and efforts, the present approach adopted by the Hong Kong libraries would appear to be more efficient taking into account their resource constraints in staff T \& D.

\section{Challenges for staff training and development}

The survey also attempted to find out whether there was any difference between the issues of concern for academic libraries in the two regions. The findings reflect that despite the libraries sharing similar views on the challenges they are encountering/will encounter, the measures adopted in the two regions could be quite diverse. Although both Chinese and Hong Kong libraries put resources and changing $\mathrm{T}$ \& D needs as their biggest challenges, the former tend to make use of internal measures to cope with the problems while the latter resorts to external collaboration at the same time. This might also be related to the different cultures and traditions of the two systems in particular, their perception towards collaboration.

Lastly, the survey looked into the level of integration of staff T \& D with other human resource management elements. Given the comparatively inflexible nature of personnel systems in public organizations of China and Hong Kong, there is not much those libraries can do to integrate staff T \& D with other HRM elements especially remuneration unless their parent institutions embark on major reform of the existing system. As expected, the respondent libraries in both regions tend to opt for more feasible ways within their limited administrative autonomy such as staffing and performance management. 


\section{Conclusion}

By looking into the literature and survey results, it can be concluded that the drastic changes in socioeconomic, cultural and technological aspects of China and Hong Kong are pushing the development of academic library systems in the two regions towards convergence over the last few decades. Despite some difference in their staff development policies and practices, the two systems generally share similar concerns and problems. With the continuous development of the Chinese library system, it is expected that the gap between the two systems will be narrowing down at a very fast speed.

The most interesting finding in this comparison will perhaps be the high average of investment by large libraries on staff T \& D. Eight out of fifteen respondents in this category reported the highest level of investment in terms of total annual staff budget. Another four indicated the second highest level; there is a total of $80 \%$ of these respondents showing a higher level of financial commitment on staff T \& D. Although this survey is unable to establish any correlation between the organization size and $\mathrm{T} \& \mathrm{D}$ investment for small to medium academic libraries due to the low response rate of those libraries, the findings for the large institutions do suggest a positive correlation in this aspect.

\section{References}

ALA Office for Research and Statistics, Spending on Staff Development (2001) [Oneline]. Retrieved 15 June 2005 from http://www.ala.org//hrdr/libraryempresources/spendingstaff.htm

Beaver, G. and Hutchings, K. (2004). The big bsiness of strategic human resource management in small business. In Stewart, J. and Beaver, G. (Eds.) HRD in Small Organizations: Research and practice (pp. 74-101). London, New York: Routledge.

Chan, J. L. Y, Yan, A. S. W. and Kan, L. B. (1996). Libraries and information centres in Hong Kong. Hong Kong : Hong Kong University Press.

Chen, X. M. (2002). College library services in the network environment. In China Society of Library Science (Ed.) Building up Chinese libraries in the $21^{\text {st }}$ Century (Vol. 2, pp. 1095-1097). Beijing: Peking Library.

Corrall,, S. (2004). Rethinking professional competence for the networked environment. In Oldroyd, M. (Ed.) Developing Academic Library Staff for Future Success (pp. 15-39), London: Facet Publishing.

Education and Manpower Bureau. (2005). The New Academic Structure for Senior Secondary Education and Higher Education - Action Plan for Investing in the Future of Hong Kong. Hong Kong: the Bureau.

Hendry, C., Arthur, M. B. and Jones, A. M. (1995). Strategy through People, London: Routledge.

Hill, R. and Stewart, J. (1999). Human resource development in small organizations, Human Resource Development International, 2(2), pp.103-123.

Ho, S. L., Liu, P. W. and Wong, R. Y.C. (1999). The Recent Trend, Problems and Resolutions of Small Mediumsized Enterprises in Hong Kong (Chinese version). Hong Kong: The Hong Kong Chinese Importers' \& Exporters' Association.

Jia, Z. S. and Li, X. L. (2002). Building up networked e-journal resources in college libraries. In China Society of Library Science (Ed.) Building up Chinese libraries in the 21 ${ }^{\text {st }}$ Century (Vol. 2, pp.858-860). Beijing: Peking Library.

Jurow, s. and Webster, D. E. (1990). Promoting management excellence in research libraries through training and staff development, Library Journal, 4(3), pp.142.

Long, J. (2004). On the quality of Librarian in the New Era, Sichuan Library Journal, vol. 140, pp. 25-27.

Lou, Y. W. (2004). Arrival of the Age for Knowledge Economy and the Enhancement of Quality for Librarians in Higher Educational Institutions, Library Information, no.8, pp.81-82.

Matlay, H. (2000). Training and the small firm. In S. Carter and D. Jones-Evans (Eds.) Enterprise and Small Business: Principles, practice and policy. Harlow: Financial Times and Prentice Hall.

Ngok, K. L. and Kwong, J. (2003). Globalization and Educational Restructuring in China. In Mok, K. H. and Welch, A. (Eds.) Globalization and Educational Restructuring in the Asia Pacific Region (pp. 160-188). New York: Palgrave Macmillan.

Ngok, K.L. and Kwong, J. (2003). Globalization and Educational Restructuring in China. In Mok, K.H. and Welch, A. (Eds.) Globalization and educational restructuring in the Asia Pacific region (pp.160-188.). Basingstoke, Hampshire; New York, N.Y.: Palgrave Macmillan.

Peng, B. C. (2002). Some thoughts on the responsibilities of digital libraries pertaining to copyright legislation after joining WTO. In China Society of Library Science (Ed.) Building up Chinese libraries in the $21^{\text {st }}$ Century (Vol.v1, pp. 460-461). Beijing: Peking Library.

Peng, S. H. (2004). Education and Development of Quality of Librarians in Higher Educational Institutions in the Information Age, Journal of Zhuzhou Teachers College, 9(2), pp.91-92, 96.

Ren, Y. Y. (2003). Library management innovations and continuing education for librarians. In China Society of Library Science (Ed.) Development and Innovation of Libraries (pp.258-261). Beijing: Peking Library.

Sadler-Smith, E. and Lean, J. (2004). The practice of HRD in smaller firms. In Stewart, J. and Beaver, G. (Eds.) HRD in Small Organizations: Research and practice (pp.124-148). London, New York: Routledge. 
Sadler-Smith, E., Down, S. and Lean, J. (2000). Modern training methods: rhetoric and reality, Personnel Review, 29(4), pp.474-490.

Sadler-Smith, E., Sargeant, A. and Dawson, A. (1998). Higher level skills training: meeting the needs of small businesses, International Journal of Training and Development, 1(4), pp.216-229.

St. Lifer, E. and Rogers,M. (1993). ULC study finds libraries invest little in staff development, Library Journal, vol. 118, pp.112.

Tan, X. J. (1997). Professional Ethics in Libraries, China Library Journal Bimonthly, no. 2, pp.4-9.

Walton, J. (1999). Strategic Human Resource Development, Harlow: Financial Times and Prentice Hall.

Wang, C. Z. (2002). How to improve the quality of library workers in higher educational institutions. In China Society of Library Science (Ed.) Building up Chinese libraries in the $21^{\text {st }}$ Century (Vol. 3, pp.1687-1688). Beijing: Peking Library.

Wang, Y. and Han R. D.(2004). Some observation on the continuing education of librarians, Shanxi Coking Coal Science \& Technology, August Supplement, pp.70-71.

Xie, J. L. (2003). Continuing education of librarians, Fujian Social Science Information, no.3, pp.39-40.

Yang, X. C. and Wang, L. L. (2004). Continuing education of librarians, Modern Information, no. 7, pp.194-197.

Yao, Z. Y. (2004). Competences of librarians and the ways to build them up, Library Information, no.8, pp.85-86.

Yao, Z. Y. (2004). The competencies for librarians and how to build them up, Library Information, no. 8, pp.8586.

Yu, G. Y. (2003). Continuing education of librarians. In China Society of Library Science (Ed.) Development and Innovation of Libraries (pp.295-298). Beijing: Peking Library.

Zhu L. Y. and Cheng, L. (2002). Keeping abreast: Innovation and development of college libraries. In China Society of Library Science (Ed.) Building up Chinese libraries in the $21^{\text {st }}$ Century (Vol. 1, pp.132-136). Beijing: Peking Library. 